\title{
Optimal Placement of Distribution Generation to Minimize Losses using Backward Forward Sweep Method in Distribution System
}

\author{
V. Shireesha, R. S. Srinivas, M. Subbarao, Polamraju V. S. Sobhan
}

\begin{abstract}
Nowadays, there is a large interest in the penetration of Distribution Generation Units in the Utility System. This penetration of Distribution Generation requires proper planning for the system while considering DG impact on the Distribution System. It requires attention towards DG location which place in the system and size of DG units. The proper location of DG should also be considered to reduce losses in the utility System. This Paper Proposes finding optimal site and size of DG in Distribution Systems and it is tested in IEEE 33 bus system. The loss reduction after placing $D G$ is shown in the results.
\end{abstract}

Keywords : Distribution System, Distributed Generation, Power Flow Technique, Loss Sensitivity Analysis, Conclusion.

\section{INTRODUCTION}

Distributed generation is not like general Electrical Power Generation System. It aims to get power on a tiny low scale on the subject of load centers that will increase power grid capability. In the Deregulated Power Market, considerations concerning the atmosphere moreover as economic problems result in increase interest towards Distribution Generation.

Distributed Generation isn't centrally Planned, It's typically connected to the Utility System and DG size could also be smaller than 50MW or 100MW. Distribution Systems has a high $\mathrm{R} / \mathrm{X}$ ratio compared to transmission systems. The many voltage drops within the distribution system end in the substantial power and the energy losses beside Distribution feeders. The Energy Loss reduction in utility Systems is one in all the best challenges within the Utility System. Earlier either reconfiguration or capacitors placement are two main techniques for loss reduction however today DG placement is supplemental within the system to cut back losses.

\section{LITERATURE SURVEY}

A technical benefit of distributed generation is in [1] Distribution generation definition presented in [3].S.K Salman discusses the impacts and losses due to embedded generation in a distribution network. [4] authors proposed a Hereford Ranch algorithm for optimal distributed generation allocation. [5] presents the PSO and Clonal algorithm for optimal location of DG.

\section{Revised Manuscript Received on September 22, 2019}

* Correspondence Author

V.SHIREESHA, $M$ Tech Student Department of EEE, ANUCET, Acharya Nagarjuna University,Guntur, India

R.S.SRINIVAS, Assistant Professor, Department Of EEE, ANUCET, Acharya Nagarjuna University, Guntur, India

M.SUBBARAO, Assistant Professor, Department Of EEE, VFSTR, Vadlamudi, Guntur, India

POLAMRAJU.V.S.SOBHAN, Associate Professor, Department Of EEE, VFSTR, Vadlamudi, Guntur, India
The simple and robust backward forward method used for the analysis of radial distribution systems is studied in [6]-[7], the optimum location and sizing of the single DG units in the radial distribution system are presented in the paper [8]. The impact of using DG placement and it's reliability is in the paper [9] and the loss minimization techniques for DG allocation studied in [10].[11] presents the Optimum location of DG and loss reduction.

This paper is sectionalized as follows: Section II discusses the loss reduction techniques in utility systems. Section III presents DG unit Sizing, In Section IV discusses the proposed technique performance and finally, the conclusion is in section $\mathrm{V}$ and followed by the references.

\section{POWER FLOW TECHNIQUES FOR DISTRIBUTION NETWORKS}

The Distributed utility system is intended in such the simplest way that it will meet the unceasingly ever-changing load with glorious reasons. The Distribution system power flow calculations are needed to attain a steady-state solution to improve system reliability. The well known simple and efficient power flow technique Backward Forward sweep Method is used for radial distribution network analysis by using MATLAB coding.

\section{MATHEMATICAL FORMULATION FOR FBS LOAD FLOW ALGORITHM}

The assumptions considered in the distribution system are as follows:

- The distribution system load is considered as three-phase balanced loads

- To make a simple analysis, the line shunt capacitance is ignored.

\section{PROPOSED METHODOLOGY}

\section{BACKWARD FORWARD SWEEP ALGORITHMIC PROGRAM}

The backward and forward sweep operations are performed in each iteration. At the same node, the voltage magnitude of every node is compared with the previous iteration voltage magnitude. If the distinction met a tolerance limit, the procedure gets stopped. Else the procedure of backward sweep, forward sweep and check for convergence is continued. Currently, the voltage values at every node and power flow within the lines are used to calculate line losses in every line segment. Before running load flow, assume line losses to be zero. 
This technique includes two steps: the backward sweep and also the forward sweep

\section{Backward Sweep:}

In this backward sweep, power flow is calculated for each branch in the backward direction from the last node to the first node by using the previous iteration voltages at every node. Here the value of voltages are held constant and updated power flows are transmitted on the feeder path in the backward direction.

1) At the 1st iteration, rated voltage values at end nodes are assumed and update these voltage values in forward sweep operation for the next iteration.

2) Start the calculations from the end node, using equation (1) first calculate node current after that using equation (2) find current from note $i$ to node $i+1$ by applying KCL.

$$
\begin{gathered}
I_{i}=\left(S_{i} / V_{i}\right)^{*} \\
I_{(i, i+1)}=I_{i+1}+\sum_{i \neq i+1} I
\end{gathered}
$$

3) By using equation (3) calculate voltage at ith node using current value from previous step.

$$
V_{\mathrm{i}}=V_{\mathrm{i}+1}+I_{(\mathrm{i} i \mathrm{i}+1)} * Z_{(\mathrm{i} i \mathrm{i}+1)}
$$

Continue this method until the junction node is reached and then store the voltage calculated at the junction node.

4) Simply follow step 2 and 3 for the remaining nodes of the system.

5) Calculate with present voltage values at the junction node in the Current using equation (1).

6) Calculate until the Reference Node is reached.

7) At the reference node, compare source voltage magnitude with calculated voltage magnitude.

Continue this process until convergence reach.

\section{Forward Sweep:}

Using the equations given below, magnitude of voltage and it's phase angles are calculated at every node ranging from source node to end node i.e., in forward path. Initially supply node voltage is taken as 1.0 per unit.

1) Start the forward sweep operation from reference node with rated voltage towards end node in forward path.

2) Using equation (4), compute node voltages.

$$
V_{i+1}=V_{i}-I_{(i, i+1)} * Z_{(i, i+1)}
$$

3) Now start backward sweep using updated voltages from forward sweep operation.

After backward forward sweep technique, node voltages and line currents are obtained, using these values line losses are calculated. Using equations (5) \& (6), complex powers $S_{i j}$ and $S_{j \mathrm{j}}$ are calculated.

$$
\begin{aligned}
& S_{i j}=V_{i} I_{i j} * \\
& S_{j i}=V_{j} I_{j i}^{*}
\end{aligned}
$$

The expressions are analyzed with reference to base load flow without any DG injection.

\section{DETERMINATION OF LOCATION AND SIZE OF DG}

The Amount of injected power at the bus is depending on the network losses which is obtained by difference between total generated power and total load i.e., by adding all $n$ bus powers. $S_{i}$ represents the bus injected power

$$
P_{L}+j Q_{L}=\sum_{i=1}^{n} S_{i}=\sum_{i=1}^{n} V_{i} I_{i}
$$

Where,

$\mathrm{P}_{\mathrm{L}} \quad$ total transmission loss

$\mathrm{Q}_{\mathrm{L}} \quad$ total reactive power loss

$\mathrm{S}_{\mathrm{i}} \quad$ bus power injected into $i^{\text {th }}$ bus

$\mathrm{V}_{\mathrm{i}} \quad$ bus voltage at $i^{\text {th }}$ bus

$\mathrm{I}_{\mathrm{i}} \quad$ bus current vector of $i^{\text {th }}$ bus

Equation (1) represents

$P_{L}+j Q_{L}=V_{\text {bus }}^{T} I_{\text {bus }}^{*}$

i.e., $\quad P_{L}+j Q_{L}=I_{b u s}^{T} Z_{b u s}^{T} I_{b u s}^{*}$

Since $\mathrm{Z}_{\text {bus }}$ is a symmetric matrix.

i.e., $\quad P_{L}+j Q_{L}=I_{\text {bus }}^{T} Z_{\text {bus }} I_{\text {bus }}^{*}$

The bus impedance matrix is nothing but sum of bus resistance matrix and a bus reactance matrix.

i.e., $Z_{\text {bus }}=R+j X$

Similarly, the bus current vector can be written as sum of real vector component and imaginary vector component as shown in equation below.

$I_{\text {bus }}=I p+j I q$

Therefore, Equation (4) can be written as

$P_{L}+j Q_{L}=(I p+j I q)^{T}(R+j X)(I p-j I q)$

From the above equation, by taking real part of the matrix we get

$P_{L}=I p^{T} R I p+I p^{T} X I p+I q^{T} R I q-I q^{T} X I q$

Where $\mathrm{X}$ is a symmetric matrix, the second and fourth terms are identical and cancel each other ,hence the simplified equation for $P_{L}$ is :

$$
P_{L}=I p^{T} R I p+I q^{T} R I q
$$




By using index notation, the equation is

$$
P_{L}=\sum_{\substack{j=1 \\ k=1}}^{n} \gamma_{j k}\left(I_{p j} I_{p k}+I_{q j} I_{q k}\right)
$$

Where $r_{j k}=$ bus resistance

The above equation shows the overall power loss in the form of bus currents. However we tend to already recognize bus powers and the bus voltages. Therefore $P_{L}$ in form of bus powers and the bus voltages as follows

For $i^{\text {th }}$ bus,

$P_{i}+j Q_{i}=V_{i} I_{i}^{*}+V_{i}\left(I_{p i}-j I_{q i}\right)$

$P_{i}+j Q_{i}=\left|V_{i}\right|\left(\operatorname{Cos} \delta_{i}+j \operatorname{Sin} \delta_{i}\right)\left(I_{p i}-j I_{q i}\right)$

Where $\mathbb{7}_{\mathrm{i}}$ is the phase angle of voltage with relation to reference bus voltage. By separating real and imagined components of the on top of equation, we get

$I_{\mathrm{pi}}=\left(1 /\left|V_{\mathrm{i}}\right|\right) *\left(P_{\mathrm{i}} \operatorname{Cos} \delta_{\mathrm{i}}+Q_{\mathrm{i}} \operatorname{Sin} \delta_{\mathrm{i}}\right)$

$I_{q i}=\left(1 /\left|V_{i}\right|\right) *\left(P_{i} \operatorname{Sin} \delta_{i}-Q_{i} \operatorname{Cos} \delta_{i}\right)$

On Substituting above equations in equation (10), we get $P_{L}$ After some algebraical operations within the following different kind

$$
P_{L}=\sum_{\substack{j=1 \\ k=1}}^{n}\left[\alpha_{j k}\left(P_{j} P_{k}+Q_{j} Q_{k}\right)+\mathbb{B}_{j k}\left(Q_{j} P_{k}-P_{j} Q_{k}\right)\right]
$$

Where $\alpha_{j k}=r_{j k} /\left|V_{j}\right| \mid V_{k} \|\left[\operatorname{Cos}\left(\delta_{j}-\delta_{k}\right)\right]$

$B_{j k}=r_{j k} /\left|V_{j}\right|\left|V_{k}\right|\left[\operatorname{Sin}\left(\delta_{j}-\delta_{k}\right)\right]$

The Incremental Transmission Loss $(I T L)_{i}$ is obtained by partial differentiation of $P_{L}$ with relation to $P_{G i}$

$(I T L)_{\mathrm{i}}=\mathscr{C P}_{L} / \mathscr{P}_{\mathrm{Gi}}$

Where $P_{L}$ is the Real Power Generated at $i^{\text {th }}$ Generating station.

At the end of mathematical manipulations, the final form of obtained $(I T L)_{i}$ can be written as

$(I T L)_{\mathrm{i}}=2 * \sum_{k=1}^{\mathrm{n}}\left(P_{k} \alpha_{i k}-Q_{k} \mathrm{~B}_{\mathrm{ik}}\right)$

Equation (19) is Known as Exact Transmission Loss Formula and $(I T L)_{i}$ is the Loss Coefficient.

\section{LOSS SENSITIVITY FACTOR METHOD}

This method works on the principle of linearization of original non-linear equation round the initial operating point to reduce the number of solution space. The values obtained using FBS power flow technique is used to compute sensitivity factors at every bus. To prepare a priority list, the busses are ranked in descending order based on sensitivity factors. The top ranked busses are to be studied first for alternative locations. The real power loss sensitivity factor with relation to real power injection is obtained by differentiating equation (19) with relation to real power injection at bus i. At every bus in the priority list, DG is located and the size is changed from small to large value till the least system losses are found.

1. First run the base load flow technique i.e., FBS method 2. Compute sensitivity factor and rank the buses in drizzling order supported sensitivity issue to create priority list.

3. Choose the bus along the priority list and place DG at the selected bus.

4. Change the DG size in small step and compute loss for every bus by running power flow analysis.

5. Compare the calculated loss with the previous answer. If the loss is a smaller amount than the previous answer, store this new answer and discard the previous answer.

6. Repeat step four to step six for all busses within the priority list.

\section{DG UNIT SIZING}

Sizing of DG is done by performing following expression which are obtained from exact loss formula in equation (19). The exact loss formula gives approximate system power loss for DG allocation at different buses. For loss estimations, only one DG is taken into count for each time. System power loss works as basic for loss optimisation additionally as location optimisation. Victimisation trial and error basis, the bus location is known because the voltage profiles within the base case helps in suggesting most popular location for DG placement. But the optimum values being prompt through equation (16) have to be compelled to be chosen for more analysis. This is often thanks to the very fact that values that deviated from the values obtained in (16) could lead to undesirable outcome that just in case will increase the losses within the system. The size of DG is such that the loss at the $i^{\text {th }}$ bus must be minimized. To get minimum losses at $i^{\text {th }}$ bus the loss coefficient $(I T L)_{i}$ must be equal to zero.

$(I T L)_{\mathrm{i}}=\left|P_{L}\right| /\left|P_{G \mathrm{i}}\right|=2 * \sum_{k=1}^{\mathrm{n}}\left(P_{k} a_{i k}-Q_{k} B_{i k}\right)=0$

It follows

$\alpha_{i k} p_{\mathrm{i}}-\mathbb{B}_{i i i} Q_{\mathrm{i}}+\sum_{\substack{k=1 \\ k \neq 1}}^{n}\left(P_{k} a_{i k}-Q_{k} \mathbb{B}_{i k}\right)=0$

$P_{\mathrm{i}}=\left(1 / \alpha_{i i i}\right)\left[\beta_{i i} Q_{\mathrm{i}}+\sum_{\substack{k=1 \\ k \neq 1}}^{n}\left(\alpha_{i k} P_{k}-\beta_{i k} Q_{k}\right)\right]$

$P_{\mathrm{i}}=P D G_{i}-P D i_{i}$

$P D G_{i}=P D_{i}+\left(1 / \alpha_{i i i}\right)\left[\beta_{i i i} Q_{i}+\sum_{\substack{k=1 \\ k \neq 1}}^{n}\left(\alpha_{i k} P_{k}-\beta_{i k} Q_{k}\right)\right]$

In the above expression, $P D G_{i}$ gives the optimal capacity of DG unit to be placed in the distribution system. 


\section{SIMULATION RESULTS}

The algorithm proposed in this paper has been tested on IEEE 33-bus system using MATLAB.

The below figure 1 represents 33 bus system.

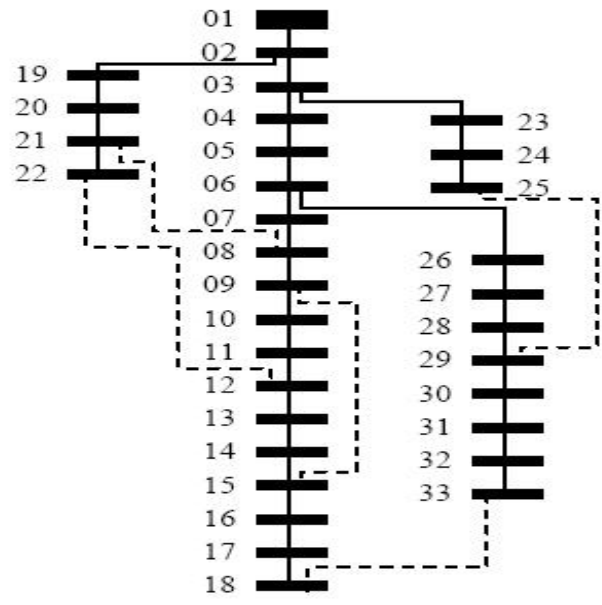

Figure 1: 33 bus system

\section{COMPARISION OF VOLTAGE PROFILES}

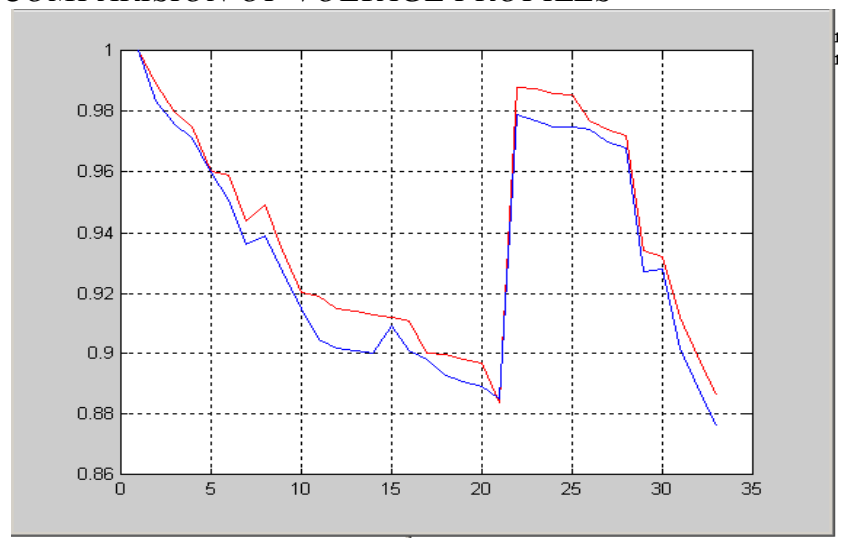

Voltage profile of 33-bus test system with and without DG The base voltage is taken as $11 \mathrm{KV}$ and base KVA is 100 . The tolerance is 0.00001 per unit. Results shown in Table 1 and 2 are active and reactive power losses in $\mathrm{KW}$ and $\mathrm{KVAR}$ respectively.

Table 1:Total active power losses

\begin{tabular}{|c|l|l|l|}
\hline $\begin{array}{l}\text { Bus } \\
\text { number }\end{array}$ & $\begin{array}{l}\text { Without } \\
\text { D.G }\end{array}$ & With D.G & $\begin{array}{l}\text { \% loss } \\
\text { reduction }\end{array}$ \\
\hline 7 & 292.47 & 173.79 & 40.58 \\
\hline 8 & 292.47 & 146.22 & 50.00 \\
\hline 9 & 292.47 & 167.88 & 42.82 \\
\hline 31 & 292.47 & 169.07 & 42.19 \\
\hline
\end{tabular}

Table 2: Total Reactive Power Losses

\begin{tabular}{|c|c|c|c|}
\hline $\begin{array}{c}\text { Bus } \\
\text { number }\end{array}$ & $\begin{array}{c}\text { Without } \\
\text { D.G }\end{array}$ & With D.G & $\begin{array}{c}\text { \% loss } \\
\text { reduction }\end{array}$ \\
\hline 7 & 196.07 & 113.32 & 42.21 \\
\hline 8 & 196.07 & 93.84 & 52.14 \\
\hline 9 & 196.07 & 107.99 & 44.92 \\
\hline 31 & 196.07 & 117.72 & 39.96 \\
\hline
\end{tabular}

It is seen that the voltage profile is considerably improved by allocating DG at optimal location in Distribution System and also the losses are reduced by $47.8 \%$. Here, the analysis during this paper suggests that the losses arising from entirely completely different placements vary greatly and thus this issue ought to be taken into thought whereas deciding applicable location for DG.

This paper shows a load flow technique to seek out the optimal location and optimal size of DG unit for voltage profile improvement and reducing power losses within the 33 bus distribution network.

This methodology is capable of analyzing the influence on some system characteristics of DG allocation and it is terribly helpful for the system designing engineer when dealing with the rise of DG penetration.

\section{REFERENCES}

1. A Review Paper on Electricity Generation from SolarEnergy.

2. An Overview on Micro grid Technology XuesongZhou, Tie Guo and Youjie Ma Key Research Laboratory for Control Theory \& Applications in ComplicatedSystems.

3. A GridInteractive Permanent Magnet Synchronous Motor Driven Solar Water Pumping System. TIA.2018. 2860564, IEEE.

4. Jain and B. Singh, "An adjustable DC link voltage based control of multi functional grid interfaced solar PV system," IEEE J. Emerg. Sel.Topics Power Electron. vol. 5, no. 2, pp. 651-660, Jun.2017.

5. A. A. A. Radwan and Y. A.-R. I. Mohamed, "Power synchronization control for grid-connected current-source inverter-based photovoltaic systems," IEEE Trans. Energy Convers., vol. 31, no. 3, pp. 1023-1036, Sep. 2016

6. Kumar, M., A.S.Devika, ., Krishnan, . K. \& Selcia, . S. (2019) symmetric stacking binary counter. International journal of communication and computer technologies, 7 (supplement 1), 11-18. Doi:10.31838/ijccts/07.sp01.03

7. MN BORHAN,'Design Of The High Speed And Reliable Source Coupled Logic Multiplexer",Journal of VLSI Circuits And Systems 1 (01), 18-22,2019

8. S. Jain, A. K. Thopukara, R. Karampuri, and V. T. Somasekhar, "A single-stage photovoltaic system for a dual-inverter-fed open end winding induction motor drive for pumping applications,"IEEE Trans. Power Electron., vol. 30, no. 9, pp. 4809-4818,Sep.2015.

9. S. S. Chandel, M. N. Naik, and R. Chandel, "Review of solar photovoltaic water pumping system technology for irrigation andcommunity drinking water supplies," Renew. Sustain. Energy Rev. vol. 49,pp. 1084-1099, Sep.2015.

10. Peng Li, Ling Zhang, Yinbo Sheng. "An effective way for large scale renewable energy power generation connected to the Grid Microgrid,"Journal of North China Electric Power University (Natura Science Edition), 2009, 01: pp.10-14.

11. XunXu, RongGao, Biping Guan, Jiangxin Zhou, Haozhong Cheng, LuFeng, Xiaoxue Gong. "Overview of Research on Planning of Micro-Grid," Power System and Cleam Energy, 2012, 07: pp.25-30.

12. G. Ganesh, G Vijay Kumar, A.R.VijayBabu, G.Srinivasa Rao, Y.R.Tagore, Performance Analysis and MPPT Control of a Standalone Hybrid Power Generation System, Journal of Electrical Engineering, Volume 15, Edition: 1, pp. 334-343, , 2015

13. Sobe A, Elmenreich W, "Smart micro grids: Overview and outlook," arXiv preprint arXiv: 1304.3944,2013.

14. Agrawal M, Mittal A, "Micro grid technological activities across the globe: A review,” Int. J. Res. Rev. Applied Sci, 2011, 7: pp. 147-152.

15. Benjamin K, Robert L, Toshifumi I. "A look at micro grid technologies and testing, projects from around the world," IEEE Power and energy magazine, 2008, pp.41-53.

16. Maheswararao, Ch Uma, YS Kishore Babu, and K. Amaresh. "Sliding mode speed control of a DC motor." 2011 International Conference on Communication Systems and Network Technologies. IEEE, 2011.




17. Sukumar, Durga, Jayachandranath Jithendranath, and Suman Saranu. "Three-level inverter-fed induction motor drive performance improvement with neuro-fuzzy space vector modulation." Electric Power Components and Systems 42.15 (2014): 1633-1646.

18. Yadlapalli, Ravindranath Tagore, and Anuradha Kotapati. "A fast-response sliding-mode controller for quadratic buck converter." International Journal of Power Electronics 6.2 (2014): 103-130. 